\title{
Croatian Students' Attitudes towards Technology Usage in Teaching Asian languages - a Field Research
}

\author{
Marijana Janjić, Sara Librenjak and Kristina Kocijan \\ Department of Information and Communication Sciences \\ Faculty of Social Sciences and Humanities Zagreb \\ marijanajanjic@yahoo.com, sara.librenjak@gmail.com, krkocijan@ffzg.hr
}

\begin{abstract}
Methodology of foreign language learning in the past 70 years tends to favor the acquisition of skills and know-how tips for the successful application in various social situations. In order to be a well-versed user of a foreign language, it is necessary to learn both grammar and syntax and on the other side, vocabulary. Today's technology enables the usage of different applications in order to achieve the objectives of teaching foreign languages. Thus students have the opportunity to use different applications either (or both) in the classroom in the presence of a teacher, or alone at home as a supplement to the classroom work.
\end{abstract}

As a part of a larger project, supported by European Social Fund, we researched Croatian students' attitudes towards technology usage in learning Asian languages. The research of attitudes is one of several goals important for our project that also includes the development of materials for e-learning, implementation of the e-tools in the classroom, and testing student's improvement in knowledge every three months. This paper deals with the first phase: a field research of students' attitudes. Our goal was to present the state-of-art of the students' self-described knowledge, issues in learning and willingness to use technology in learning. We plan to compare these results to empirical results in later phases of the project.

Croatian students $(\mathrm{N}=203)$ studding in Zagreb, Rijeka, Varaždin and Split participated in the survey, answering a number of questions on the use of modern technology in Japanese $(\mathbf{N}=104)$, Korean $(\mathbf{N}=46)$, Hindi $(\mathbf{N}=32)$ and Sanskrit $(\mathbf{N}=21)$. They expressed their views on questions related to specific difficulties in learning vocabulary, grammar or writing system of a particular language. They also answered questions about their attitude towards teaching materials such as course books and general attitudes about technology in learning. We used students' feedback into account during the process of developing ematerials for each of the mentioned Asian languages.

\section{INTRODUCTION}

It was in the 18th century that Alexander von Humboldt suggested that the language could not be taught but that one can only create conditions for learning to take place. Three centuries later, deep into the digital era, it seems that we are still not recognizing the power of technology and its usage for creating such languagelearning oasis.
Language teaching techniques (have your students repeat after you, use a limited vocabulary initially, help students practice reading and speaking, teach language through pictures to make it meaningful) proposed by Jan Comenius, the famous Czech language teacher, in the 17 th century are still valid techniques that may easily be embedded into e-tools. And although many teachers are trying their best to make their language classrooms innovative and implement all the possibilities technology offers such as CALL, MALL, GALL, etc. [1], there are still many of them who underestimate not just the power of technology but also their students' needs, learning habits and attitudes on e-learning in general.

We believe that student's learning needs and learning styles have to be taken into account when preparing learning materials since the main purpose of teaching is to help someone learn. That is why we asked Croatian students of Asian languages to tell us how they perceive e-learning and which aspects of learning one or several Asian languages do they find difficult and challenging. After we analyzed the anonymous student survey results, we created e-learning materials that could be implemented in the classroom and/or as a side learning material for students' individual use to help them cope with some of the issues they stated in the survey. We expect our students to easier acquire the language of their choice, and subsequently perform better on their tests, when exposed to materials that facilitate their learning. Their progress is monitored weekly and tested every three months.

We considered two main factors while developing both survey and learning materials: 1. learning new language requires learning and memorizing new vocabulary, 2 . it also requires learning and memorizing new grammatical and syntactic patterns. It is relevant to note that both students and teachers share these goals. Another goal that is shared by probably everyone in the foreign language discourse is the need to be practical: be practical in teaching, be practical in learning, and focus on practical skills and knowledge. Practical here is taken as a synonym for application of skills and knowledge in language classroom, that are both from teacher's and student's point of view rated as relevant and useful outside of the classroom for purposes for which student 
requires them. Our idea is to see if and how technology can be useful in attaining these goals in order to help both students and teachers.

In the following sections, we will give more details about the survey we conducted and explain the results we got from the survey dividing them into two main topics (issues in language learning and attitudes towards elearning technologies). We will conclude the paper with some final remarks.

\section{STUDENT SURVEY}

Motivation and attitudes towards learning have often been quoted as relevant for student's success in education in general [2], [3], and thus their relevance in CALL or other technology enhanced learning environments should not come as a surprise. For that reason we were very keen to learn about the reasons that attract Croatian students toward the study of one (or more) Asian languages, their aims and goals as well as the relevant learning experiences that they have had thus far in language classroom with their teachers and technology input.

Two hundred and three students in total, studying Hindi, Japanese, Korean or Sanskrit or several of these languages simultaneously (see Table 1), have participated in a survey. The survey had been anonymous in order to protect their privacy and not make them vulnerable in their later contacts with their teachers, since teachers have been given the opportunity to see the survey results. Most of the students are young adults, $45 \%$ of them aged 1923 , and $20 \%$ aged 24-28. Although majority of students are taking regular college classes at the Faculty of Humanities and Social Sciences in Zagreb, many of them also invest time and resources in the continuing education and thus enroll in language schools, take private classes with tutors etc. A number of students, attending Japanese course in Varaždin, Rijeka or Split have also took part in the survey as well as the first generation of students enrolled in Japanese course at the University of Pula.

Table 1. Total number of students in the survey.

\begin{tabular}{|c|c|c|}
\hline Gender & Number & $\%$ \\
\hline Male & 48 & $24 \%$ \\
\hline Female & 152 & $75 \%$ \\
\hline Undeclared & 3 & $1 \%$ \\
\hline Total & 203 & $100 \%$ \\
\hline
\end{tabular}

One of the first things we wanted to learn about students of Asian languages is how long have they been learning a particular language. The candidates were asked to give an estimate of learning hours they have invested in the learning process prior to their participation in our project. We wanted to see how long does the average learner spend learning the language, and to see if there are differences in the speed of progress after we implement the second phase of the project. The average result shows that 242.8 learning hours (at the high school or university) are behind the majority of them, which means that they have been learning a particular language for more than two years. This estimation is based on the classroom hours and self study. Thus, their motivation cannot be described as lacking, especially since many of them are aware of a particular goal they want to achieve with the language course they are taking. The three most important students' goals can be summed up as: a) to achieve a working proficiency in the particular language, b) to communicate with native speakers, c) to visit or live in a country where a particular language is spoken. Some students have been determined enough to try their luck with several teachers, various course books and various resources. Taken altogether, students included in the survey can be described as well motivated individuals to learn a particular language, as an average individual had over 240 learning hours in at least one of the Asian languages of his/her choice.

\section{ISSUES IN LEARNING}

There are several categories of learning issues that we were interested in including script, speech production, grammar, memorizing the vocabulary, speech understanding, pronunciation, and writing and composition. We will show here how these issues differ across languages and explain possible reasons for them.

All of our survey participants have a Croatian language as a mother tongue and thus they use Latin script for written communication. On the other side, this is not the case for any of the Asian languages that we are interested in this project (Japanese, Korean, or Indian languages). Of course, as it would be quite natural to assume, this presents the first obstacle in learning the language. This is especially true for Japanese language, which uses three different scripts - an obstacle that can be challenging to overcome to many learners.

Table 2. Level of difficulty in learning a script (student survey).

\begin{tabular}{|c|c|c|}
\hline Language & Script & Average difficulty rating \\
\hline Japanese & Hiragana & 1,91 out of 5 \\
\hline Japanese & Katakana & 2,68 out of 5 \\
\hline Japanese & Kanji & 4,29 out of 5 \\
\hline Korean & Hangeul & 2,0 out of 5 \\
\hline Hindi / Sanskrit & Devanagari & 2,57 out of 5 \\
\hline
\end{tabular}

However, according to our survey results, all but one script (kanji) has scored the difficulty level lower than 3 out of 5 (where 1 is not difficult at all and 5 is extremely difficult) (Table 2.). Korean script Hangeul is not rated as very difficult to learn, with the average difficulty rating of 2 out of 5. Devanagari, Indian script, seems to be somewhat more difficult to learn and is rated 2.57 out of 5. In the case of the Japanese, hiragana script is considered relatively simple (1.9/5), while katakana, the script used for foreign words, is considered a bit more difficult (2.7/5). The third Japanese script, ideographic 
kanji script that consists of around 2000 characters, is rated as the most difficult script to learn (4.3/5). To overcome this difficulty in learning kanji, we prepared some multimedia solutions that are presented in more details in [4].

Representations of the difficulty rating of different scripts are given in Table 2 while the most common issues in learning are presented in Figures 1, 2, 3 and 4 for Japanese, Korean, Hindi and Sanskrit, respectively.

Contrary to Croatian, which is highly flective language with seven cases, three genders and complex verb systems, East-Asian languages generally do not possess the case and gender system or many complex verb tenses. Japanese and Korean are agglutinative languages with SOV word order, and the syntactic relations between words are expressed with particles. What can be problematic in language learning of these languages is the difference in language logic and pragmatics that influence the grammar. For example, students of Japanese consider honorific speech system as the most difficult element in grammar learning, because Croatian language (besides the $t i-V i$ difference in politeness $^{1}$ ) does not possess such a system.

Most students also report having difficulties in using and understanding particles, different verb endings, and some tenses which are expressed with one tense in Croatian, while in Japanese there are several ways of expressing different nuances of the tense (e.g. conditional).

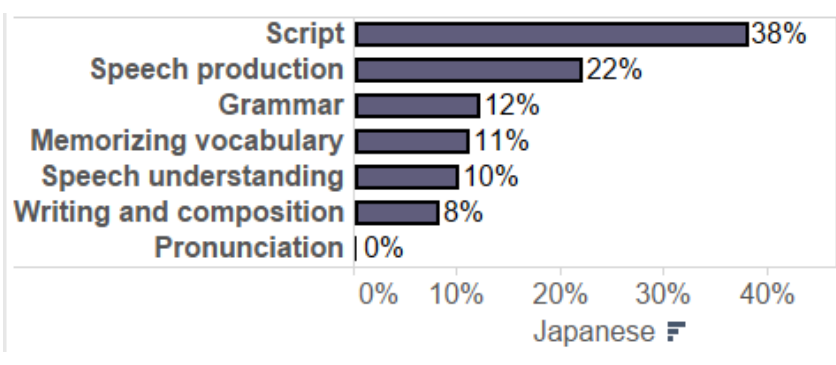

Figure 1. Japanese students' issues with the acquisition of grammar and syntax

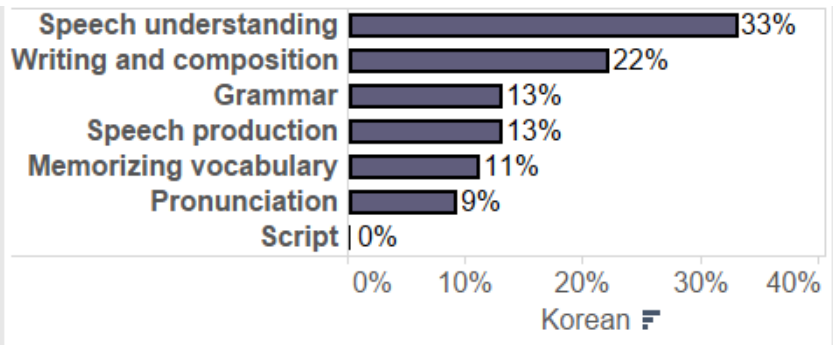

Figure 2. Korean students' issues with the acquisition of grammar and syntax

Although Hindi and Sanskrit are Indo-Aryan languages, students experience issues in learning these

\footnotetext{
${ }^{1}$ In Croatian language, there is a difference in grammatical forms while addressing older people or strangers, made by using different pronouns and verb endings. In those situations instead of using forms to denote second person singular, one uses markers of second person plural.
}

languages just as in learning Korean and Japanese. For these learners, speech production, writing and composition seem to present the biggest issues (see Figures 3 and 4). It is very interesting that Sanskrit students have marked writing and composition as an issue at all, as students are generally not asked to produce written compositions in Sanskrit. Their study of Sanskrit is rather the opposite of it, as they translate numerous texts from Sanskrit into Croatian.

Speech understanding is also highly problematic to Hindi learners but not so much for Sanskrit learners. Contrary again to Sanskrit grammar, Hindi grammar does not appear to be so difficult to learn. Students learning Sanskrit are facing more difficulties with the pronunciation than their fellow students of Hindi who do not find this area of language highly problematic.

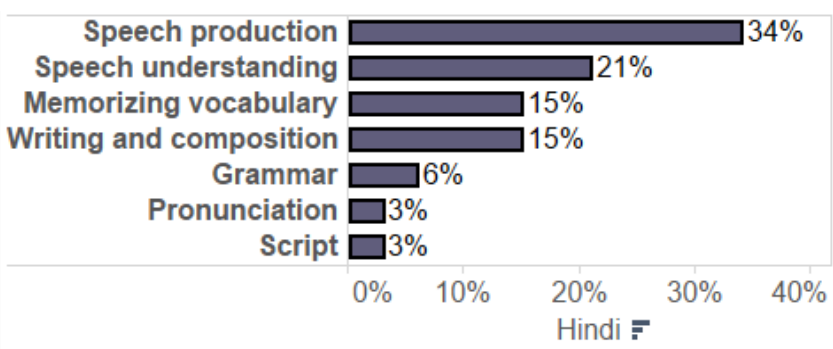

Figure 3. Hindi students' issues with the acquisition of grammar and syntax

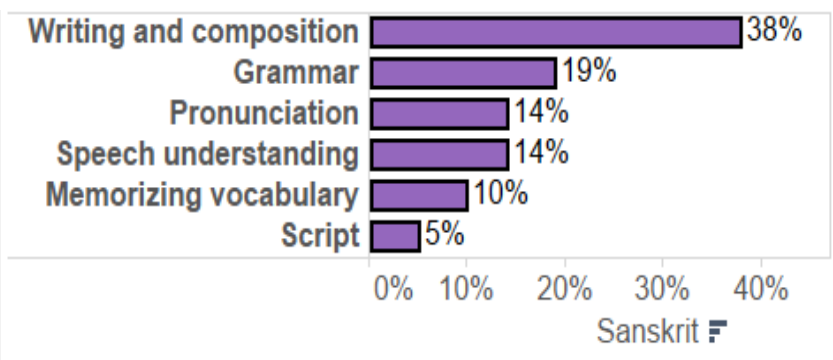

Figure 4. Sanskrit students' issues with the acquisition of grammar and syntax

\section{ATTITUDES TOWARDS E-LEARNING}

The following set of questions was intended for finding about student's e-learning attitudes. We asked them about the amount of time they spend on Internet in order to learn something, not just the language. The results are ordered by the score obtained for each of the categories (Figure 5). Their answers were chosen on the scale from 1 to 5 , where 1 is "Not relevant at all" and 5 is "I find it very relevant for myself".

Results for each question are above 3.60, which shows positive attitude towards their study and different elements of that study (teacher, course book, selfsatisfaction). Use of Internet for educational purposes is also very high, 4.20 on average. Similarly, when we asked about relevance they would give to learning on mobile devices, such as smartphones, their estimation 
was almost identical 4.1. Their attitude towards use of such devices in language learning was very positive, with an average score of 4.5. Again, this information should not come as a surprise since most of them spend a lot of time in the proximity of mobile devices and over $60 \%$ of students engage with their mobile devices at least three to four times an hour.

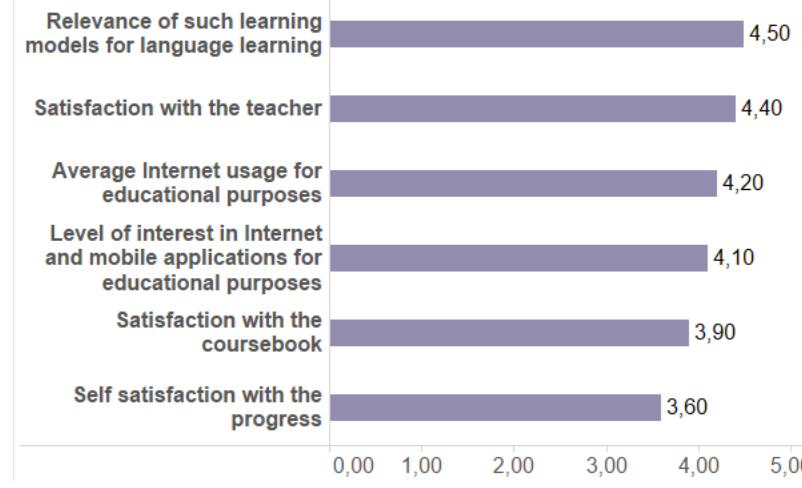

Figure 5. Students' attitudes on learning process and use of Internet and other tools.

On the other hand, only 48 out of 203 students, mostly students of Japanese language, had had a chance to engage with e-tools in their language classrooms. The results seem to be disparate, and even more so, since more than few students are aware of the potential resource that could be put in use for language learning: Duolingo, Memrise, Quizlet, Anki, Lang8, WaniKani. Resources such as Busuu, Cram, Pleco, Lingvist.io, FluentU, etc. also made it to the list of resources, when students were asked about them. It should be noted that in the second phase of the project, we used Memrise and Quizlet to develop our own materials for learning, using Croatian language and a relevant language pair. We choose these two environments due to their high quality, previous exposure with students, and adaptability in developing materials.

Apart from surveys, we also conducted testing of students' skills prior to the exposure to e-materials developed by us. They were developed in the already created environment for e-learning (Memrise and Quizlet).

By the time of writing this paper, the pre-exposure testing had been followed by only one after-exposure testing. It is thus too early to say how much the existence of e-learning materials has influenced students' results. We hope that the two additional after-exposure tests, which will be conducted in April and July 2016, will give us insight that is more relevant.

\section{CONCLUSION}

A number of studies anticipate positive results from the usage of technology in classroom for various purposes. Taylor (1980) and Stevenson (2008) have shown that a computer can be implemented in the classroom as either a teacher, tutee (environment), tool or a resource [5]. Several empirical studies in Croatia have shown that e-technology can be implemented well in the language teaching and teaching in general [4], [6], [7], [8], [9] and [10].

Still, there are teachers who do not use these tools for their classes, in spite of all the development of e-learning tools and materials, which already assumes the confident use of technology by both teachers and students. There are many reasons why technology should be used in the classroom and we will name here three that we find the most important: 1) it enhances teaching and learning process; 2) students learn how to use technology with the tools they are going to need in their work place; 3) students' needs are better cared for. This can further be supported with the fact that the technology is already omnipresent and it has an effect on the way people perceive information, look for information, use it, create it or learn it [11].

The question is then why the classrooms are already not swarming with materials developed for e-learning as an enhancement for the learning process. Could it be that the answer mainly lies with the teacher as several studies have shown that the interest and attitudes of teachers are also relevant [12], [13], and [14]. Namely, if teachers do not feel comfortable with technology and do not support its usage, there is not a lot that students can do even if they would like to use e-materials.

Due to the fact that we are living in the 21 st century, it is valid to ask if we, as educators, are depriving our students of needed knowledge. Are we failing to educate a 21 st century student? In other words, although we would like to think we are better skilled in the use of technology than our students are, they probably have a better inside information on it than us, and use it more proficiently than many of us will ever be able to.

Now, imagine a 21 st century student, accustomed to learning from everything in his/her surrounding with the help of technology (from newest song or video on YouTube to a late-night chat with someone on the other side of the globe), being made to learn a language with the same type of resources our parents used, before technology explosion. There is nothing inviting or exciting in such an approach for many of them, and as the survey shows, they are aware of how technology can be implemented for educational purposes, as they are accustomed to using it on their own accord. The question is thus not so much whether students are ready to accept e-tools in language learning, but whether teachers are. Since the studies suggest that some teachers avoid technology because of their lack of skills, the good way to solve the situation would be to invest in teachers' training. There are several papers that suggest the same solution, and we as a team have created an experimental workshop for teachers at the Faculty, involved in teaching various languages, to teach them how to use Memrise and Quizlet as tools in their teaching. The anonymous survey at the end of the workshop showed that $100 \%$ of the attendants were interested in learning more about similar topics in an organized manner.

It is important to note that students' willingness to employ a certain tool in the learning process does exist 
and the survey we have conducted confirms that. It has to be met by educators' attitudes towards it [15] in order to turn it into a profitable (for both student and teacher) learning-teaching tool. We are aware of issues related to the successful implementation of e-tools and e-learning materials into the classroom, but new beginnings have never been easy in any field of work. And that has never before stopped the humankind to learn and prosper.

\section{ACKNOWLEDGMENT}

This work was supported by the European Social Fund; grant agreement no HR.3.2.01.-0040.

\section{REFERENCES}

[1] N. Saqlain. "Technology and Foreign Language Pedagogy: what the literature

http://er.educause.edu/articles/2012/6/technology-and-foreignlanguage-pedagogy-what-the-literature-says

[2] E. Ushida. "The Role of Students' Attitudes and Motivation in Second Language Learning in Online Language Courses." CALICO Journal 23(1), pp. 49-78, 2005. https://journals.equinoxpub.com/index.php/CALICO/article/view/2 3165/19170

[3] B. Bellés-Fortuño, N. O. Ramírez. "Motivation: A key to success in the foreign language classroom? A case study on vocational training and higher education English courses." 1st International Conference on Higher Education Advances, HEAd'15, 2015. DOI:http://dx.doi.org/10.4995/HEAd15.2015.431

[4] S. Librenjak, K. Vučković, Z. Dovedan Han. Multimedia assisted learning of Japanese kanji characters. Proceedings of the 35th International Convention MIPRO, Rijeka, 2012, pp. 1284-1289.

[5] J. Simpson, A. Walker. "New Technologies for English Language Learning and Teaching." Routledge Companion to English Studies. Eds. C. Leung, B.V. Street. 475-489, 2014.
[6] Z. Dovedan, S. Seljan, K. Vučković, "Multimedia in Foreign Language Learning", Proceedings of the $25^{\text {th }}$ International Convention MIPRO 2002: MEET + MHS, Rijeka, 2002, pp.72-75

[7] E. Družijanić Hajdarević, K. Vučković., Z. Dovedan. Računalo ili raćunalo uz pomoć računala. Proceedings of the 29th International Convention MIPRO, Rijeka, 2006, pp. 283-287.

[8] T. Lauc., S. Matić, N. Mikelić. Educational multimedia software for English language vocabulary. Proceedings of the 1st International Conference on Multidisciplinary Information Sciences and Technologies: InSciT2006, Vol. I: Current Research in Information Sciences and Technologies Multidisciplinary approaches to global information systems, Merida, 2006, pp. 117 121.

[9] M. Leko, S. Kiš̌ček, J. Knežević, I. Martinović, P. K. Marić, E Vusić. Interactive Application for Learning the Latin Language. InFuture 1, 2013, pp. 237-248

[10] S. Sendra, J. M. Jiménez, L. Parra, J. Lloret. Blended Learning in a Postgraduate ICT course. 1st International Conference on Higher Education Advances, HEAd'15, 2015. DOI:http://dx.doi.org/10.4995/HEAd15.2015.491

[11] G. Bautista, A Escofet. "Competences for Teaching and Learning in an e-Learning Setting." International Handbook of e-Learning, Vol. 1 : Theoretical Perspectives and Research. Eds. B.H. Khan, M. Ally, 171-179, 2015.

[12] C. Baubeng-Andoh. "Factors influencing teachers' adoption and integration of information and communication technology into teaching: A review of the literature." International Journal of Education and Development using Information and Communication Technology, Vol. 8, Issue 1, 136-155, 2012.

[13] F. Bordbar. "English teachers' attitudes toward computer assisted language learning." International Journal of Language Studies, Vol. 4 (3), 27-54, 2010.

[14] H. Peralta, F.A. Costa. "Teachers' competence and confidence regarding the use of ICT." Educational Sciences Journal, Vol. 3, 75-84, 2007.

[15] G. Wiebe, K. Kabata. "Students' and instructors' attitudes toward the use of CALL in foreign language teaching and learning." Computer Assisted Language Learning 23(3), 221-234, 2010. 